\title{
Learning curve of totally laparoscopic distal gastrectomy for gastric cancer: a single teaching hospital study
}

\author{
Feng Chi, Yuefu Lan, Shenkang Zhou, Leilei Yang, Miaoliang Chen, Tienan Bi \\ Department of Gastrointestinal Surgery, Taizhou Hospital of Zhejiang Province, China \\ Videosurgery Miniinv 2018; 13 (4): 442-447 \\ DOI: https://doi.org/10.5114/wiitm.2018.78965
}

\begin{abstract}
Introduction: Totally laparoscopic distal gastrectomy (TLDG) for gastric cancer has gradually gained popularity. However, the learning curve of TLDG is rarely reported.

Aim: To determine the learning curve of TLDG for gastric cancer.

Material and methods: We retrospectively reviewed and analyzed the medical records of 80 patients with gastric cancer who underwent TLDG with lymph node dissection from January 2016 to December 2017. We divided the patients into four groups based on when they underwent TLDG: group A (cases 1-20), group B (cases 21-40), group $C$ (cases 41-60), and group D (cases 61-80). Comparative analyses of clinical data, including clinicopathologic characteristics, operative data, and postoperative course, were performed for these groups.

Results: No significant difference was observed between the groups in various clinicopathologic characteristics. Total operative time for group $A(168.3 \pm 14.6 \mathrm{~min})$ was significantly longer than for groups $B(152.5 \pm 10.5 \mathrm{~min}), C(154.2$ $\pm 11.6 \mathrm{~min})$, and $D(155.3 \pm 10.8 \mathrm{~min})$, but there was no significant difference between groups $B, C$, and $D$. Anastomosis time for group $A(27.5 \pm 12.4 \mathrm{~min})$ was significantly longer than for groups $B(15.3 \pm 4.6 \mathrm{~min}), C(16.6 \pm 5.7 \mathrm{~min})$, and $D(15.4 \pm 4.5 \mathrm{~min})$, but there was no significant difference between groups $B, C$, and $D$. Non-anastomosis time, estimated blood loss, retrieved lymph nodes, time to first flatus, time to first oral intake, and postoperative hospital stay and complications showed no difference between the four groups.

Conclusions: An experience of approximately 20 cases of TLDG was required to complete the learning curve.
\end{abstract}

Key words: learning curve, totally laparoscopic distal gastrectomy, gastric cancer.

\section{Introduction}

Since it was first reported by Kitano in 1994 [1], laparoscopy-assisted distal gastrectomy (LADG) has become gradually accepted as standard surgery for early gastric cancer located in the lower third of the stomach in several Asian countries, especially in China, Japan, and in Korea [2-7]. There are many advantages of LADG over conventional open gastrectomy, including better visualization, less pain, less bleeding, and shorter hospital stay [8, 9]. Currently, because several studies have demonstrated that LADG for advanced gastric cancer is technically feasible and oncologically safe, its indication has extended from early gastric cancer to advanced gastric cancer $[10,11]$. With the development of laparoscopic instruments, surgeons who have experience with LADG cautiously perform totally laparoscopic distal gastrectomy (TLDG) [12, 13]. The LADG, unlike TLDG, requires an epigastrium auxiliary incision for safe en bloc resection of the specimen and to finish the reconstruction of the digestive tract, while TLDG enables both resection and anastomosis to be performed intracorporeally using a laparoscopic tech- 
nique. Several studies have reported the advantages of TLDG over LADG, such as the need for a small incision, less invasiveness, and faster recovery [14-16]. However, it is noteworthy that intracorporeal anastomosis is an advanced laparoscopic procedure that involves a significant learning curve. Several studies have described the learning curve of LADG [17-19]. Some demonstrated that an experience of 40 to 60 cases of LADG was required to achieve proficiency and to reach a learning curve plateau [17, 18]. Learning curve effects of LADG were reported to be observed with operative time, estimated blood loss, retrieved lymph nodes, and postoperative morbidity $[18,20,21]$. However, studies on the learning curve of TLDG are rare.

\section{Aim}

The aim of the study was to discuss the learning curve of totally laparoscopy distal gastrectomy for gastric cancer.

\section{Material and methods}

This was a retrospective study involving consecutive patients who underwent TLDG for primary gastric cancer in a single teaching hospital. The study was approved by the institutional review board of our hospital, and the patients provided informed consent before participating in the study. The medical records of all patients with gastric cancer who underwent TLDG from January 2016 to December 2017 were collected. All procedures were performed by the same three-person surgical team, comprising one surgeon and two assistants. The surgeon had experienced about 40 cases of LADG but had no experience with TLDG. Before the surgery, all patients underwent endoscopic assessment, including biopsy. All patients were evaluated using computed tomography of the chest and abdomen. Patients who had undergone palliative treatment, preoperative chemotherapy or radiotherapy, or patients with inadequate data, were excluded.

\section{Variables}

Patient clinicopathologic characteristics included age, gender, body mass index (BMI), American Society of Anesthesiologists (ASA) score, tumor location, tumor size, pTNM stage (American Joint Committee on Cancer, $7^{\text {th }}$ edition [22]), range of lymph node dissection, and reconstruction type of the gastrointestinal tract. Data on the operative time, estimated blood loss, number of retrieved lymph nodes, and the postoperative outcomes (such as time to first flatus, time to first oral intake, duration of postoperative hospital stay, and postoperative complications) were collected and analyzed to evaluate the quality of the procedures. Operative time included anastomosis time, non-anastomosis time, and total operative time. Postoperative complications included 30-day morbidity and mortality. Only complications of grade II or higher (graded by the Clavien-Dindo classification [23]) were regarded as events.

\section{Surgical techniques}

The surgical procedure was standardized before the beginning of the study. Under general anesthesia, patients lay in the supine position. The surgeon stood on the left side of the patient, the first assistant was on the right, and the laparoscopist stood between the abducted legs of the patient. A 12-mm trocar was inserted through an infraumbilical incision using an open method. After pneumoperitoneum was achieved, two right $5-\mathrm{mm}$ assistant ports and two left operator ports (5-mm lower and 12-mm upper) were inserted under laparoscopy. After inspection of the peritoneal cavity, the stomach was mobilized via lymphadenectomy according to the Japanese gastric cancer guidelines [24]. The duodenum and the distal two-thirds of the stomach were transected intracorporeally using endoscopic linear staplers. Methods of anastomosis included Billroth I or Roux-en-Y reconstruction. Roux-en-Y reconstruction was used when tension in the anastomotic portion was expected. Otherwise, Billroth I reconstruction was preferred. Intracorporeal Billroth I reconstruction was performed using a delta-shaped anastomosis, as reported by Kanaya et al. [12]. In Roux-en-Y reconstruction, all anastomoses were performed using endoscopic linear staplers with or without a hand-suturing technique. The resection specimen was obtained through the umbilical wound.

\section{Statistical analysis}

All data were analyzed using IBM SPSS Statistics version 22.0 (IBM Co., Armonk, NY, USA). Data are presented as the mean \pm standard deviation for continuous variables and as percentages for categorical 
variables. The Mann-Whitney $U$ test and Student's $t$ test were performed to analyze continuous variables. The $\chi^{2}$ test was used to analyze categorical variables. The one-way analysis of variance and the least significant difference test were used for comparing continuous variables in multiple comparisons. A $p$ value of $<0.05$ (two-sided) was considered statistically significant.

\section{Results}

From January 2016 to December 2017, 84 patients underwent TLDG for primary gastric cancer and there was no conversion to open surgery. After all exclusions, 80 patients were enrolled in this study. The patients were divided into four groups according to when they underwent TLDG. Each group consisted of 20 patients: group A (case 1-20), group B (case 21-40), group $C$ (case 41-60), and group D (case 61-80).

The clinicopathologic characteristics of the patients are summarized in Table I.

Regarding various clinicopathologic characteristics, such as age, gender, BMI, ASA score, tumor location, tumor size, pTNM stage, range of lymph node dissection, and reconstruction type, no signifi-

Table I. Clinicopathologic characteristics of patients

\begin{tabular}{|c|c|c|c|c|c|}
\hline Parameter & $\begin{array}{l}\text { Group A } \\
(n=20)\end{array}$ & $\begin{array}{l}\text { Group B } \\
(n=20)\end{array}$ & $\begin{array}{l}\text { Group C } \\
(n=20)\end{array}$ & $\begin{array}{l}\text { Group D } \\
(n=20)\end{array}$ & $P$-value \\
\hline Age (years) & $61.4 \pm 9.9$ & $63.0 \pm 8.4$ & $64.4 \pm 9.5$ & $63.9 \pm 8.9$ & 0.749 \\
\hline Gender, $n(\%)$ : & & & & & 0.581 \\
\hline Male & $14(70)$ & $13(65)$ & $11(55)$ & $15(75)$ & \\
\hline Female & $6(30)$ & $7(35)$ & $9(45)$ & $5(25)$ & \\
\hline $\mathrm{BMI}\left[\mathrm{kg} / \mathrm{m}^{2}\right]$ & $22.9 \pm 2.8$ & $24.1 \pm 2.9$ & $23.2 \pm 3.5$ & $22.6 \pm 2.8$ & 0.434 \\
\hline ASA score, $n(\%)$ : & & & & & 0.828 \\
\hline I & $10(50)$ & $8(40)$ & $11(55)$ & $10(50)$ & \\
\hline$\|$ & $9(45)$ & $8(40)$ & $7(35)$ & $8(40)$ & \\
\hline III & $1(5)$ & $4(20)$ & $2(10)$ & $2(10)$ & \\
\hline Tumor location, $n(\%)$ : & & & & & 0.630 \\
\hline Lower & $17(85)$ & $18(90)$ & $16(80)$ & $15(75)$ & \\
\hline Middle & $3(15)$ & $2(10)$ & $4(20)$ & $5(25)$ & \\
\hline Tumor size $[\mathrm{cm}]$ & $3.0 \pm 1.9$ & $2.6 \pm 1.1$ & $2.9 \pm 1.4$ & $2.7 \pm 1.2$ & 0.783 \\
\hline pTNM stage, $n(\%):$ & & & & & 0.783 \\
\hline- & $12(60)$ & $8(40)$ & $9(45)$ & $7(35)$ & \\
\hline$\alpha$ & $5(25)$ & $8(40)$ & $6(30)$ & $8(40)$ & \\
\hline$\beta$ & $3(15)$ & $4(20)$ & $5(25)$ & $5(25)$ & \\
\hline Range of LN dissection, $n$ (\%): & & & & & 0.853 \\
\hline $\mathrm{D} 1+$ & $4(20)$ & $3(15)$ & $2(10)$ & $3(15)$ & \\
\hline $\mathrm{D} 2$ & $16(80)$ & $17(85)$ & $18(90)$ & $17(85)$ & \\
\hline Reconstruction type, $n$ (\%): & & & & & 0.928 \\
\hline Billroth & $17(85)$ & $18(90)$ & $18(90)$ & $17(85)$ & \\
\hline Roux-en-Y & $3(15)$ & $2(10)$ & $2(10)$ & $3(15)$ & \\
\hline
\end{tabular}

$B M I$ - body mass index, ASA - American Society of Anesthesiologists, $L N$ - lymph node. 
Table II. Operative data of patients

\begin{tabular}{|lccccc|}
\hline Parameter & Group A $(n=20)$ & Group B $(n=20)$ & Group C $(n=20)$ & Group D $(n=20)$ & $P$-value \\
\hline $\begin{array}{l}\text { Total operative } \\
\text { time [min] }\end{array}$ & $168.3 \pm 14.6$ & $152.5 \pm 10.5$ & $154.2 \pm 11.6$ & $155.3 \pm 10.8$ & $<0.001^{*}$ \\
\hline $\begin{array}{l}\text { Anastomosis time } \\
\text { [min] }\end{array}$ & $27.5 \pm 12.4$ & $15.3 \pm 4.6$ & $16.6 \pm 5.7$ & $15.4 \pm 4.5$ & $<0.001^{* *}$ \\
\hline $\begin{array}{l}\text { Non-anastomosis } \\
\text { time [min] }\end{array}$ & $140.8 \pm 6.7$ & $137.2 \pm 8.6$ & $137.5 \pm 9.1$ & $139.8 \pm 9.2$ & 0.469 \\
\hline $\begin{array}{l}\text { Estimated blood } \\
\text { loss [ml] }\end{array}$ & $57.0 \pm 30.1$ & $65.2 \pm 27.9$ & $64.0 \pm 21.8$ & $61.7 \pm 30.2$ & 0.794 \\
\hline $\begin{array}{l}\text { Number of } \\
\text { retrieved lymph } \\
\text { nodes }\end{array}$ & $35.1 \pm 12.7$ & $32.6 \pm 9.2$ & $33.4 \pm 11.5$ & $35.2 \pm 11.7$ & 0.851 \\
\hline
\end{tabular}

*Subgroup comparisons: $A, B, p<0.001 ; A, C, p<0.001 ; A, D, p=0.002 ; B, C, p=0.640 ; B, D, p=0.421 ; C, D, p=0.758$. * Subgroup comparisons: $A, B, p<$ $0.001 ; A, C, p<0.001 ; A, D, p<0.001 ; B, C, p=0.420 ; B, D, p=0.918 ; C, D, p=0.466$.

cant difference was noted between the four groups $(p>0.05)$. Therefore, the baseline between the four groups was balanced.

We compared operative data between the four groups (Table II). The total operative time in group A $(168.3 \pm 14.6 \mathrm{~min})$ was significantly longer than in groups B (152.5 \pm 10.5 min, A, B $p<0.001)$, C (154.2 $\pm 11.6 \mathrm{~min}, A-C p<0.001)$, and $D(155.3 \pm 10.8 \mathrm{~min}$, $A-D p=0.002)$, but there was no significant difference between groups $B, C$, and D $(p>0.05)$. Similarly, the anastomosis time in group $A(27.5 \pm 12.4 \mathrm{~min})$ was significantly longer than in groups $B(15.3 \pm 4.6$ $\min , A, B p<0.001), C(16.6 \pm 5.7 \mathrm{~min}, A-C p<0.001)$, and $D(15.4 \pm 4.5 \mathrm{~min}, A-D p<0.001)$, but there was no significant difference between groups $B, C$, and $D$ $(p>0.05)$. The non-anastomosis times for groups $A$, $B, C$, and D were $140.8 \pm 6.7,137.2 \pm 8.6,137.5 \pm 9.1$, and $139.8 \pm 9.2 \mathrm{~min}$, respectively, with no significant difference observed between them ( $p=0.469)$. Changes in operative time are shown in Figure 1.
There was no difference in estimated blood loss $(p=0.794)$ or the number of retrieved lymph nodes ( $p=0.851)$ between the groups.

The postoperative course of the patients is illustrated in Table III. Five complications were observed,

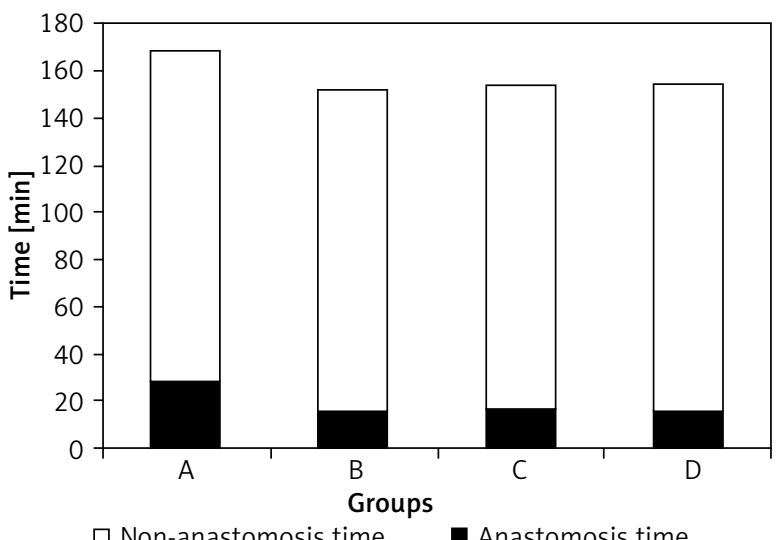

Figure 1. Changes in operative time of totally laparoscopic distal gastrectomy (TLDG)

Table III. Postoperative course of patients

\begin{tabular}{|lccccc|}
\hline Parameter & Group A $(n=20)$ & Group B $(n=20)$ & Group C $(n=20)$ & Group D $(n=20)$ & $P$-value \\
\hline Time to first flatus [days] & $3.0 \pm 0.8$ & $3.0 \pm 0.8$ & $2.9 \pm 0.8$ & $2.8 \pm 0.8$ & 0.846 \\
\hline Time to first oral intake [days] & $6.4 \pm 1.5$ & $7.1 \pm 1.9$ & $7.2 \pm 1.6$ & $6.5 \pm 2.0$ & 0.389 \\
\hline Postoperative hospital stay [days] & $8.8 \pm 1.9$ & $9.4 \pm 2.5$ & $9.6 \pm 2.1$ & $8.6 \pm 2.2$ & 0.413 \\
\hline \begin{tabular}{l} 
Complications, $n$ (\%): \\
\hline Delayed gastric emptying
\end{tabular} & $2(10)$ & 0 & $1(5)$ & $2(10)$ & 0.504 \\
\hline Ileus & 1 & 0 & 0 & 1 & 0 \\
\hline Pulmonary infection & 0 & 0 & 0 & 1 & \\
\hline
\end{tabular}


which included two cases of delayed gastric emptying, two cases of ileus, and one case of pulmonary infection, but there was no postoperative mortality. These complications were controlled using conservative treatment. No significant difference was observed between the groups in terms of morbidity rate $(p=0.504)$ or other postoperative outcomes, such as time to first flatus ( $p=0.846)$, time to first oral intake $(p=0.389)$, and postoperative hospital stay $(p=0.413)$.

\section{Discussion}

There are concerns about the oncological safety of TLDG because of doubts regarding whether TLDG can achieve the same quality of lymph node dissection as can be achieved with open surgery [25]. It is well known that the quality of lymph node dissection should be evaluated by the number of retrieved lymph nodes $[26,27]$. More than 15 retrieved lymph nodes are necessary for proper tumor, node, and metastasis staging [22]. In the present study, the number of retrieved lymph nodes was not influenced by the number of cases. The mean number of retrieved lymph nodes per patient in each group which could achieve disease cure and could determine lymph node metastasis was $35.1 \pm 12.7,32.6 \pm 9.2,33.4$ \pm 11.5 , and $35.2 \pm 11.7$ for groups $A, B, C$, and $D$, respectively. This result indicated that dissection of lymph nodes around the stomach can be performed efficiently using TLDG and that the surgical quality of TLDG, in terms of oncologic outcome, could be maintained during the learning stage.

In the present study, estimated blood loss and postoperative course were not influenced by the number of cases, indicating that the surgical quality and short-term outcomes of TLDG were not sacrificed during the learning stage. This favorable result was believed to be mainly the result of the standardized laparoscopic procedure and an established educational system $[28,29]$. Our institution introduced and standardized TLDG in 2013. In the educational system of our hospital, the trainee should participate in at least 30 procedures as the camera assistant and 30 procedures as the first assistant before performing LADG as a surgeon. After performing 30 LADG procedures as a surgeon, the trainee could start performing TLDG as a surgeon. In this study, all procedures were performed by a single surgeon using standardized surgical techniques as described above.
The total operative time was significantly different between groups $A$ and $B, A$ and $C$, and $A$ and $D$, but there was no significant difference between groups $B$ and $C, B$ and $D$, or C and D, which indicates that the surgeon reached a learning plateau after the first 20 procedures. Therefore, the learning curve of TLDG in this study could be inferred as 20 cases. Similar to total operative time, anastomosis time decreased significantly and remained at a relatively low level after the first 20 cases. However, non-anastomosis time was not influenced by the number of cases. This can be explained by the fact that the surgical procedure other than anastomosis was similar between LADG and TLDG. Therefore, we considered the reduction in total operative time to be due to a decrease in anastomosis time and because the learning curve for intracorporeal anastomosis had been overcome.

The present study had several limitations. First, it was retrospective and nonrandomized. Second, data were obtained from a center with a high volume of patients, which may have influenced the results. Therefore, it may be difficult to adapt the results of our study to other institutes. Future well-designed multi-center prospective studies will enhance the understanding of the learning curve of TLDG.

\section{Conclusions}

The learning curve of TLDG for surgeons who have experience with LADG is about 20 cases. However, the surgical quality of TLDG can be maintained during the learning stage.

\section{Conflict of interest}

The authors declare no conflict of interest.

\section{References}

1. Kitano S, Iso Y, Moriyama M, Sugimachi K. Laparoscopy assisted Billroth I gastrectomy. Surg Laparosc Endosc 1994; 4: 146-8.

2. Hu Y, Ying M, Huang C, et al. Oncologic outcomes of laparoscopy-assisted gastrectomy for advanced gastric cancer: a largescale multicenter retrospective cohort study from China. Surg Endosc 2014; 28: 2048-56.

3. Yu J, Hu Y, Chen T, et al. Laparoscopic distal gastrectomy with D2 dissection for advanced gastric cancer. Chin J Cancer Res 2013; 25: 474-6.

4. Lin JX, Huang CM, Zheng CH, et al. Laparoscopy-assisted gastrectomy with D2 lymph node dissection for advanced gastric cancer without serosa invasion: a matched cohort study from South China. World J Surg Oncol 2013; 11: 4 
5. Lee JH, Nam BH, Ryu KW, et al. Comparison of outcomes after laparoscopy-assisted and open total gastrectomy for early gastric cancer. Br J Surg 2015; 102: 1500-5.

6. Yamashita K, Sakuramoto S, Kikuchi S, et al. Laparoscopic versus open distal gastrectomy for early gastric cancer in Japan: long-term clinical outcomes of a randomized clinical trial. Surg Today 2015; 46: 741-9.

7. Ben-David K, Tuttle R, Kukar M, et al. Laparoscopic distal, subtotal gastrectomy for advanced gastric cancer. J Gastrointest Surg 2015; 19: 369-74.

8. Takiguchi S, Fujiwara Y, Yamasaki M, et al. Laparoscopy-assisted distal gastrectomy versus open distal gastrectomy. A prospective randomized single-blind study. World I Surg 2013; 37: 2379-86.

9. Smolarek S, Salih A, Kazanowski M, et al. Laparoscopic assisted total gastrectomy for gastric cancer - operative technique. Videosurgery Miniinv 2015; 10: 133-7.

10. Hamabe A, Omori T, Tanaka K, Nishida T. Comparison of longterm results between laparoscopy-assisted gastrectomy and open gastrectomy with D2 lymph node dissection for advanced gastric cancer. Surg Endosc 2012; 26: 1702-9.

11. Young KP, Hong MY, Young-Woo K, et al. Laparoscopy-assisted versus Open D2 Distal Gastrectomy for Advanced Gastric Cancer: results From a Randomized Phase II Multicenter Clinical Trial (COACT 1001). Ann Surg 2018: 267: 638-45.

12. Kanaya S, Gomi T, Momoi H, et al. Delta-shaped anastomosis in totally laparoscopic Billroth I gastrectomy: new technique of intraabdominal gastroduodenostomy. J Am Coll Surg 2002; 195: 284-7.

13. Oki E, Sakaguchi Y, Ohgaki K, et al. Feasibility of delta-shaped anastomoses in totally laparoscopic distal gastrectomy. Eur Surg Res 2011; 47: 205-10.

14. Ikeda O, Sakaguchi Y, Aoki Y, et al. Advantages of totally laparoscopic distal gastrectomy over laparoscopically assisted distal gastrectomy for gastric cancer. Surg Endosc 2009; 23: 2374-9.

15. Kinoshita T, Shibasaki H, Oshiro T, et al. Comparison of laparoscopy-assisted and total laparoscopic Billroth-I gastrectomy for gastric cancer: a report of short-term outcomes. Surg Endosc 2011; 25: 1395-401.

16. Song KY, Park CH, Kang HC, et al. Is totally laparoscopic gastrectomy less invasive than laparoscopy-assisted gastrectomy? Prospective, multicenter study. J Gastrointest Surg 2008; 12: 1015-21.

17. Kunisaki C, Makino H, Yamamoto N, et al. Learning curve for laparoscopy-assisted distal gastrectomy with regional lymph node dissection for early gastric cancer. Surg Laparosc Endosc Percutan Tech 2008; 18: 236-41.

18. Kim MC, Jung GJ, Kim HH. Learning curve of laparoscopy-assisted distal gastrectomy with systemic lymphadenectomy for early gastric cancer. World J Gastroenterol 2005; 11: 7508-11.

19. Qian F, Sun G, Tang B, et al. Learning curve of laparoscopic radical gastrectomy for gastric cancer. Chin J Minim Invasive Surg 2008; 8: 510-2.

20. Fujiwara M, Kodera Y, Miura S, et al. Laparoscopy-assisted distal gastrectomy with systemic lymph node dissection: a phase II study following the learning curve. J Surg Oncol 2005; 91: 26-32.
21. Jin SH, Kim DY, Kim H, et al. Multidimensional learning curve in laparoscopy-assisted gastrectomy for early gastric cancer. Surg Endosc 2007; 21: 28-33.

22. Washington $\mathrm{K}$. 7th edition of the AJCC cancer staging manual: stomach. Ann Surg Oncol 2010; 17: 3077-9.

23. Dindo D, Demartines N, Clavien PA. Classification of surgical complications: a new proposal with evaluation in a cohort of 6336 patients and results of a survey. Ann Surg 2004; 240 : 205-13.

24. Japanese Gastric Cancer Association. Japanese gastric cancer treatment guidelines 2010 (ver. 3). Gastric Cancer 2011; 14: 113-23.

25. Chen K, Xu XW, Mou YP, et al. Systematic review and meta-analysis of laparoscopic and open gastrectomy for advanced gastric cancer. World J Surg Oncol 2013; 11: 182.

26. Kodera Y, Fujiwara M, Ohashi N, et al. Laparoscopic surgery for gastric cancer: a collective review with meta-analysis of randomized trials. J Am Coll Surg 2010; 211: 677-86.

27. Memon MA, Khan S, Yunus RM, et al. Meta-analysis of laparoscopic and open distal gastrectomy for gastric carcinoma. Surg Endosc 2008; 22: 1781-9.

28. Nunobe S, Hiki N, Tanimura S, et al. The clinical safety of performing laparoscopic gastrectomy for gastric cancer by trainees after sufficient experience in assisting. World I Surg 2013; 37: 424-9.

29. Tokunaga M, Hiki N, Fukunaga T, et al. Learning curve of laparoscopy-assisted gastrectomy using a standardized surgical technique and an established educational system. Scand J Surg 2011; 100: 86-91.

Received: 28.07.2018, accepted: 26.08.2018. 